\title{
Article
}

\section{UDP-Glycosyltransferases from the UGT344 Family Are Involved in Sulfoxaflor Resistance in Aphis gossypii Glover}

\author{
Kangsheng Ma ${ }^{1,2}$, Qiuling Tang ${ }^{1}$, Pingzhuo Liang ${ }^{1}$, Jianhong $\mathrm{Li}^{2}$ and Xiwu Gao ${ }^{1, *(\mathbb{D}}$ \\ 1 Department of Entomology, China Agricultural University, Beijing 100193, China; txma1986@163.com (K.M.); \\ tangqiuling1145@163.com (Q.T.); liangpingzhu@126.com (P.L.) \\ 2 Hubei Insect Resources Utilization and Sustainable Pest Management Key Laboratory, College of Plant \\ Science and Technology, Huazhong Agricultural University, Wuhan 430070, China; jianhl@mail.hzau.edu.cn \\ * Correspondence: gaoxiwu@263.net.cn; Tel.: +86-010-6273-2974
}

Citation: Ma, K.; Tang, Q.; Liang, P.; Li, J.; Gao, X. UDPGlycosyltransferases from the UGT344 Family Are Involved in Sulfoxaflor Resistance in Aphis gossypii Glover. Insects 2021, 12, 356. https://doi.org/10.3390/ insects12040356

Academic Editor: Cam Donly

Received: 22 January 2021

Accepted: 9 March 2021

Published: 16 April 2021

Publisher's Note: MDPI stays neutral with regard to jurisdictional claims in published maps and institutional affiliations.

Copyright: (c) 2021 by the authors. Licensee MDPI, Basel, Switzerland. This article is an open access article distributed under the terms and conditions of the Creative Commons Attribution (CC BY) license (https:// creativecommons.org/licenses/by/ $4.0 /)$.
Simple Summary: The cotton aphid, Aphis gossypii Glover, is a notorious pest in cotton and cucurbit fields. The control of $A$. gossypii has typically relied on the application of chemical insecticides. Sulfoxaflor is the first commercially available sulfoximine insecticide, which exhibits great efficacy against sap-feeding insect pests and has been applied as an alternative insecticide for controlling of $A$. gossypii in China. Consequently, A. gossypii quickly developed resistance to this insecticide. Hence, in this study, to clarify the potential detoxifying roles of UGTs (one of the phase II detoxification enzymes) in resistance of $A$. gossypii against sulfoxaflor, the synergistic effects of two synergists (sulfinpyrazone and 5-nitrouracil) against sulfoxaflor were investigated using the susceptible and laboratory-established sulfoxaflor resistant strain (SulR), and the expression levels of 15 UGT genes were determined by qRT-PCR. Furthermore, the involvement of highly upregulated UGTs in sulfoxaflor-resistant strain was functionally tested by RNA interference (RNAi). Our results suggest that overexpression of UGTs contributes to sulfoxaflor resistance in A. gossypii, which should be useful for understanding sulfoxaflor resistance mechanisms.

Abstract: UDP-glycosyltransferases (UGTs) are major phase II detoxification enzymes that catalyze the transfer of glycosyl residues from activated nucleotide sugars to acceptor hydrophobic molecules and play very important roles in the biotransformation of various endogenous and exogenous compounds. Our previous studies demonstrated that UGTs participated in the detoxification of insecticides in Aphis gossypii. However, the potential roles of UGTs in A. gossypii resistance to sulfoxaflor are still unclear. In this study, two inhibitors of UGT enzymes, sulfinpyrazone and 5-nitrouracil, significantly increased the toxicity of sulfoxaflor to a resistant strain of A. gossypii, whereas there were no synergistic effects in the susceptible strain. Based on the transcriptome sequencing results, the expression levels of 15 UGTs were analyzed by quantitative real-time PCR, and we found that seven UGT genes were highly over-expressed in a sulfoxaflor-resistant strain compared to the susceptible strain, including UGT344B4, UGT344C5, UGT344A11, UGT344A14, and UGT344L2. Further suppressing the expression of UGT344B4, UGT344C5, and UGT344A11 by RNA interference significantly increased the sensitivity of resistant aphids to sulfoxaflor, indicating that the overexpression of UGT genes is potentially associated with sulfoxaflor resistance. These results could provide valuable information for further understanding the mechanisms of insecticide resistance.

Keywords: UDP-glycosyltransferase; insecticide resistance; sulfoxaflor; Aphis gossypii; RNAi

\section{Introduction}

The cotton aphid, Aphis gossypii Glover (Hemiptera: Aphididae), is a notorious pest in cotton and cucurbit fields throughout the world. It causes great economic losses both through directly feeding and indirectly by virus transmission and contamination of honeydew [1]. The control of $A$. gossypii has typically relied on the application of chemical 
insecticides [2-4]. Consequently, cotton aphids have evolved very high levels of resistance to a range of chemical insecticides, such as organophosphates, carbamates, pyrethroids, and neonicotinoids [5-9].

In the last few decades, synthetic organic insecticides have been widely used to control insect pests in agriculture and horticulture worldwide [10-15], and many insect pests have developed resistance to several types of chemical insecticides [16-21], which is a great challenge for controlling of these pests effectively. It is well known that insects have developed four types of resistance mechanisms to chemical insecticides: metabolic resistance, target-site resistance, penetration resistance, and behavioral resistance [22]. Among these mechanisms, the enhanced detoxification mediated by the overproduction of detoxifying enzymes, including cytochrome P450 monooxygenases (P450s), esterases (ESTs), and glutathione $S$-transferases (GSTs), could result in pest resistance to multiple insecticide classes [4,23-27]. For example, the overexpression of a carboxylesterase gene contributes to omethoate resistance in A. gossypii [23]. The overexpression of multiple P450 genes, especially CYP6ER1, has been found to be involved in the resistance of Nilaparvata lugens to imidacloprid, thiamethoxam, sulfoxaflor, and clothianidin [28-33]. The elevated activities of carboxylesterases confer resistance to organophosphates, pyrethroids, and carbamates in Myzus persicae [24,34-36]. Recently, the involvement of UDP-glycosyltransferases (UGTs) in secondary metabolism was also reported in several insect pests [37-41].

UGTs are a superfamily of enzymes found in animals, plants, fungi, and bacteria that catalyze the conjugation of a range of diverse small lipophilic compounds with sugars to produce glycosides, generating water-soluble products and resulting in the detoxification and elimination of their substrate [42-46]. At first, UGTs were found to play very important roles in the detoxification of plant secondary metabolites in insects [47-50]. Recently, several studies have demonstrated that UGTs might be associated with insecticide resistance [41,51-55]. For instance, the overexpression of UGT2B17 (renamed UGT33AA4) is involved in chlorantraniliprole resistance in Plutella xylostella [40,41], and the upregulation of UGT genes was proved to be associated with imidacloprid resistance in Diaphorina citri [54]. Our previous studies also found that UGTs potentially contributed to imidacloprid resistance in A. gossypii [10,38]. Sulfoxaflor is a sulfoximine insecticide, which is widely used in the control of A. gossypii in China [56,57]. Our long-term resistance monitoring results show that field populations of $A$. gossypii collected from cotton fields in China had evolved low to moderate levels of resistance to sulfoxaflor. The further resistance mechanism study indicated that overexpression of multiple P450 genes contribute to sulfoxaflor resistance [4]. However, whether UGTs are involved in sulfoxaflor resistance in A. gossypii has not been determined.

In the present study, to clarify the potential roles of UGTs in resistance of $A$. gossypii to sulfoxaflor, the synergistic effects of two synergists (sulfinpyrazone and 5-nitrouracil) against sulfoxaflor were investigated by using the susceptible and laboratory established sulfoxaflor-resistant strain (SulR), and the transcriptional levels of 15 UGT genes were determined by qRT-PCR. Furthermore, the involvement of highly overexpressed UGTs in the sulfoxaflor-resistant strain was functionally tested by RNA interference (RNAi). Our results suggest that overexpression of UGTs can also contribute to the sulfoxaflor resistance in A. gossypii, which should be useful for understanding sulfoxaflor resistance mechanisms. In addition, these results might facilitate further study of the functions of UGTs in insecticide resistance.

\section{Materials and Methods}

\subsection{Insects}

Two strains of $A$. gossypii used in this study were established in the laboratory using the same original field population collected in 2016 from cotton fields in Xinjiang Uygur Autonomous Region, China. One strain was susceptible to sulfoxaflor (SS) and the other strain was resistant to sulfoxaflor (SulR), which was established from the Shawan population by continual selection with increased concentration of sulfoxaflor based on the $\mathrm{LC}_{50}$ values [4]. 
All aphids were reared on cotton seedlings, Gossypium hirsutum (L.), in the laboratory at $22 \pm 1{ }^{\circ} \mathrm{C}$, with $60 \%$ relative humidity and a photoperiod of $16: 8 \mathrm{~h}$ (light:dark).

\subsection{Chemicals}

Sulfoxaflor (97.9\%) was obtained from Dow AgroSciences (Indianapolis, Indiana, USA); two inhibitors of UGT enzymes, sulfinpyrazone (SUL) and 5-nitrouracil (5-NU), and Triton X-100 were purchased from Sigma-Aldrich (Saint Louis, MO, USA). Other chemicals and reagents used in this study were analytical grade reagents.

\subsection{Toxicity Bioassays}

The toxicities of the sulfoxaflor to SS and SulR populations were evaluated by using the leaf-dipping method [58] with slight modifications [4]. The stock solution of sulfoxaflor was prepared in acetone and adjusted to the desired concentrations by serial dilution with distilled water containing $0.05 \%(v / v)$ Triton X-100 for the bioassays. Fresh cotton leaves were cut into $20 \mathrm{~mm}$ diameter leaf discs using a sharpened steel punch. The leaf discs were then dipped in the desired concentration of sulfoxaflor or in $0.05 \%(v / v)$ Triton X-100 water for $15 \mathrm{~s}$ as a control. The treated leaf discs were placed in the shade and allowed to air dry, and then placed upside down onto the agar beds $(1.5 \mathrm{~mL}$ of $2 \%$ agar) in the 12 -well cell culture plate. Finally, healthy apterous adult aphids were carefully transferred onto the leaf discs and covered with Chinese art paper to prevent escape. All bioassays were carried out in the laboratory at $22 \pm 1{ }^{\circ} \mathrm{C}$ with a photoperiod of $16: 8 \mathrm{~h}$ (light:dark), the same as the insect rearing. The treatment for each concentration was performed with three replicates, and at least 30 aphids were used for each replicate. The mortality was recorded at $48 \mathrm{~h}$ after treatment. The $\mathrm{LC}_{50}$ values were calculated by probit analysis using POLO Plus 2.0 statistical software (LeOra Software Inc., Berkeley, CA, USA).

\subsection{Synergism Bioassays}

To reveal the potential role of UGTs in metabolic resistance against sulfoxaflor, the synergistic effects of sulfinpyrazone (SUL) and 5-nitrouracil (5-NU) were investigated using the bioassay method described above. The maximum sublethal doses of SUL and 5-NU for the susceptible strain were determined using the above-mentioned bioassay method, and the maximum doses that led to zero mortality in the susceptible strain were adopted as the maximum sublethal concentrations in the present study. Healthy apterous adult aphids were exposed to cotton leaf discs that were treated with SUL or 5-NU (at the maximum sublethal concentration) and the sulfoxaflor mixtures. The final concentration of SUL and $5-\mathrm{NU}$ were $80 \mu \mathrm{g} \mathrm{mL}^{-1}$. The mortality was recorded at $48 \mathrm{~h}$ after treatment. The probit analysis was conducted using POLO Plus 2.0 statistical software and the synergistic ratio (SR) was calculated by dividing the $\mathrm{LC}_{50}$ values without the synergist by the $\mathrm{LC}_{50}$ values with synergist.

\subsection{Quantitative Real-Time PCR and Data Analysis}

The relative expression levels of UGT genes in the SS and SulR strains were determined using quantitative real-time PCR (qRT-PCR). Total RNA of cotton aphids was isolated using TRIzol ${ }^{\circledR}$ reagent (Invitrogen, Carlsbad, CA, USA) following the manufacturer's instructions, and first-strand cDNA was synthesized from 1.0 ug total RNA using the PrimeScript RT reagent kit with gDNA Eraser (Takara Biotechnology, Dalian, China), and stored at $-20{ }^{\circ} \mathrm{C}$. qRT-PCR was performed on an Applied Biosystems 7500 Real-Time PCR system (Applied Biosystems, Foster City, CA, USA) using SYBR ${ }^{\circledR}$ Premix Ex Taq ${ }^{\mathrm{TM}}$ (Tli RNaseH Plus) (Takara Biotechnology, Dalian, China). The qRT-PCR reactions and the thermocycling program were described in our previous publications $[4,59]$. The experiment was conducted with three technical replications and three independent biological replicates. The housekeeping genes elongation factor 1 alpha $(E F 1 \alpha)$ and beta actin $(\beta-A C T)$ were used as internal reference genes in this study [60]. The relative gene expression was calculated using the $2^{-\Delta \Delta C t}$ method [61]. 


\subsection{UGT Genes Silencing and Bioassays}

Primer design and synthesis methods for dsRNA production were described in our previous publication [4]. The gene fragments of four highly overexpressed UGT genes (UGT344B4, UGT344C5, UGT344A11, and UGT344L2) were amplified using specific primers conjugated with the T7 RNA polymerase promoter (Table 1). The products of RT-PCR were used as templates for dsRNA synthesis using the MEGAscriptRNAi kit (Ambion, Austin, USA). The dsRNA of GFP was synthesized under the same conditions as the UGT genes. For the dsRNA feeding experiments, dsRNA was added to an artificial diet $\left(0.5 \mathrm{~mol} \mathrm{~L}^{-1}\right.$ sterile sucrose solution) at a final concentration of $100 \mathrm{ng} \mu \mathrm{L}^{-1}$. The artificial diet containing DEPC water and $100 \mathrm{ng} \mu \mathrm{L}^{-1} d s G F P$ were used as the control. At least fifty healthy apterous adults of SulR strain were used for each dsRNA feeding experiments. The experiments were performed in triplicate. To determine the efficiency of dsRNA knockdown of target UGT genes, the living aphids were collected after feeding for $48 \mathrm{~h}$, and then the samples were used for qRT-PCR analysis. To assess the sensitivity of $A$. gossypii to sulfoxaflor after RNAi of UGT genes, fifty resistant adult aphids that fed on dsRNA incorporated artificial diets for $48 \mathrm{~h}$ were transferred onto cotton leaf discs that had been treated with a sulfoxaflor solution of $130 \mathrm{mg} \mathrm{L}^{-1}$ (approximate concentration of $\mathrm{LC}_{50}$ value of sulfoxaflor to SulR). The mortality was recorded after exposure to sulfoxaflor for $48 \mathrm{~h}$. Each treatment was replicated in triplicate.

Table 1. Primers used for qRT-PCR analysis and dsRNA synthesis.

\begin{tabular}{|c|c|c|}
\hline Primer Name & Forward Primer $\left(5^{\prime}-3^{\prime}\right)$ & Reverse Primer $\left(5^{\prime}-3^{\prime}\right)$ \\
\hline$E F 1 \alpha$ & GAAGCCTGGTATGGTTGTCGT & GGGTGGGTTGTTCTTTGTG \\
\hline$\beta$-Actin & GGGAGTCATGGTTGGTATGG & TCCATATCGTCCCAGTTGGT \\
\hline UGT344C5 & GCCGAATCCAGCAACAGTAT & TTCATGAACACCAACGACGG \\
\hline UGT344B4 & GGTTCGTGGGTCACTACTCC & TTGCCCATCTAGTATCTTCTCA \\
\hline UGT344D6 & GTCAGCCCATCTATTATCTTCC & GGCGGGTTTCAGGTGTAT \\
\hline UGT344L2 & TCCGCCGTTCCCAAGAC & CCACCGACACTAACAACATTCG \\
\hline UGT344A11 & GCCAAGCACGGAAGTCA & ACGCACTCGGACACCAG \\
\hline UGT344A14 & GGGACTTGAAGGTTAGGG & ATCGGTGACGGAATGAC \\
\hline UGT343A4 & TCATAACTCACGGAGGATTG & GCACTTCTTTGACGGCATT \\
\hline UGT343B2 & CCGTCAATGGTCTGGGTC & TGAGCGTTCATCAGCGTTA \\
\hline UGT343C2 & ATCCGTCCACTTTACCA & TGAATCCCACTTCCACA \\
\hline UGT342A2 & CAAAGCCACTGTTGCCTAAT & AATACGCTGGTGCTGTTTC \\
\hline UGT342C2 & AAACGACGCTCAACTAACCA & GGAGCCGAGCAATTCTGT \\
\hline UGT349A2 & CGGTGGACTGTTAGGGGTA & CGCATTTATAGCGTAACTGTCA \\
\hline UGT350A2 & CACAGTGTTGAAGAGGCAGT & AGCAGCTCCTCTAGATTCCA \\
\hline UGT350B2 & САTCTATTCCAAATGCTGGTG & TGACGGTCGTGTCTCCC \\
\hline UGT350C2 & AAAATGCCCAAGGAAACAG & GGGAACTCCGTGATAGACG \\
\hline UGT350C3 & GTGTCGCAGTGGCAAGG & CGTTCTGGAGCATCGTCT \\
\hline \multirow{2}{*}{ 344C5-RNAi } & taatacgactcactatagggAG & taatacgactcactatagggAC \\
\hline & CACAAGTACCTCAGAGAGT & AACTGATTCTGCTGGTGAC \\
\hline \multirow{2}{*}{ 344B4-RNAi } & taatacgactcactatagggACG & taatacgactcactatagggGA \\
\hline & ATGAGTAGAATGCTGTGC & CTTGCCGGTTCGATTGTA \\
\hline \multirow{2}{*}{ 344L2-RNAi } & taatacgactcactatagggTATG & taatacgactcactatagggATT \\
\hline & AGTGCTGTGCTTCGAG & GTTGACACCGTTGCTGG \\
\hline \multirow{2}{*}{ 344A11-RNAi } & taatacgactcactatagggTGGAC & taatacgactcactatagggCG \\
\hline & ATGAACGGATGGTGA & TGCCGATTCAGTGATGAA \\
\hline
\end{tabular}

\subsection{Data Analysis}

The gene expression data were analyzed using Student's $t$-test for significant differences between the sulfoxaflor-susceptible and -resistant strains, and $p<0.05$ was considered to be statistically significant. One-way analysis of variance (ANOVA), with Tukey's multiple comparisons, was used to compare the RNAi silencing efficiency and the effect of the dsRNA treatments on insecticide susceptibility. All statistical analysis was completed using the GraphPad InStat 3.0 software (GraphPad Software, San Diego, CA, USA). 


\section{Results}

\subsection{Synergism of Sulfinpyrazone and 5-Nitrouracil}

The synergisms of SUL and 5-NU to sulfoxaflor were evaluated by the leaf-dipping method, and the results are summarized in Table 2. Both SUL and 5-NU exhibited no significant synergism against sulfoxaflor in the susceptible strain (SS), while these two synergists significantly increased the toxicity of sulfoxaflor in the SulR strain by 2.01- and 3.78 -fold, respectively (Table 2$)(p<0.05)$. It suggests that UDP-glycosyltransferases may be associated with the resistance of $A$. gossypii against sulfoxaflor.

Table 2. Synergistic effects of 5-NU and SUL on the toxicity of sulfoxaflor in the susceptible and sulfoxaflor resistant strains of Aphis gossypii.

\begin{tabular}{|c|c|c|c|c|c|c|}
\hline Strains & $\begin{array}{c}\text { Insecticide + } \\
\text { Synergist }\end{array}$ & Slope \pm SE $^{\mathrm{a}}$ & $\begin{array}{c}\mathrm{LC}_{50}(95 \% \mathrm{CL}) \\
\left(\mathrm{mg} \mathrm{L}^{-1}\right)^{\mathrm{b}}\end{array}$ & $x^{2}$ & $d f$ & $\mathrm{SR}^{\mathrm{c}}$ \\
\hline \multirow[t]{3}{*}{ SS } & Sulfoxaflor & $1.18 \pm 0.15$ & $0.40(0.24-0.57)$ & 9.37 & 16 & \\
\hline & Sulfoxaflor $+5-\mathrm{NU}$ & $0.93 \pm 0.14$ & $0.32(0.14-0.51)$ & 4.84 & 16 & 1.28 \\
\hline & Sulfoxaflor + SUL & $0.96 \pm 0.14$ & $0.35(0.17-0.58)$ & 18.36 & 19 & 1.14 \\
\hline \multirow[t]{3}{*}{ SulR } & Sulfoxaflor & $1.05 \pm 0.16$ & $131.30(90.59-209.20)$ & 11.38 & 16 & \\
\hline & Sulfoxaflor $+5-\mathrm{NU}$ & $1.09 \pm 0.14$ & $65.40(47.34-90.29)$ & 13.63 & 16 & 2.01 \\
\hline & Sulfoxaflor + SUL & $1.75 \pm 0.33$ & $34.74(13.58-52.39)$ & 23.69 & 16 & 3.78 \\
\hline
\end{tabular}

${ }^{a} \mathrm{SE}$ : standard error; ${ }^{\mathrm{b}} \mathrm{CL}$ : confidence limits; ${ }^{\mathrm{c}} \mathrm{SR}$ : synergism ratio $=\mathrm{LC}_{50}$ of sulfoxaflor $/ \mathrm{LC}_{50}$ of sulfoxaflor with synergist.

\subsection{Expression Profiles of Aphis Gossypii UGT Genes in the Susceptible and Resistant Strains}

Thirty-one UGT genes from the SS and SulR strains of A. gossypii were identified based on our previous transcriptomic sequencing results, and six of them were overexpressed in SulR strain (Supplementary Materials). To investigate which UGT genes may be involved in sulfoxaflor detoxification, the mRNA levels of 15 UGT genes in the susceptible and resistant strains were analyzed by quantitative real-time PCR. The results show that the transcripts of seven UGT genes were significantly upregulated in the SulR strain compared with the SS strain $(p<0.05)$ (Figure 1), among which four UGT344 family genes were increased more than two-fold. Specifically, the levels of UGT344B4, UGT344C5, and UGT344A11 were increased to 4.40-, 4.09-, and 3.02-fold, respectively (Figure 1). In contrast, the transcripts levels of UGT342A2 and UGT350C2 were downregulated in the SulR strain compared with the SS strain (Figure 1).



Figure 1. Relative expression levels of UGT genes in adult aphids of the susceptible and sulfoxaflor resistant strains. Data are presented as the mean \pm SD for at least three independent replicates. ** indicates significant differences as analyzed by Student's $t$-test $(p<0.05)$; ${ }^{* * *}$ indicates significant differences as analyzed by Student's $t$-test $(p<0.01)$. 


\subsection{Effects of UGT Gene Suppression on the Sensitivity of Aphis Gossypii to Sulfoxaflor}

To evaluate the functional roles of overexpressed UGT genes in A. gossypii resistance against sulfoxaflor, the expression levels of four UGT344 family genes were depressed by RNAi in the sulfoxaflor resistant strain, and the susceptibility to sulfoxaflor was determined after dsRNA feeding treatments. After resistant cotton aphids were fed on dsRNA incorporated diet for $48 \mathrm{~h}$, the expression levels of UGT344B4, UGT344C5, UGT344A11, and UGT344L2 were reduced to 0.68-, 0.53-, 0.56-, and 0.64-fold compared to that of the control, which only contained $d s G F P$ (Figure 2). The toxicity of sulfoxaflor to aphids significantly increased after the treatment by feeding the dsUGT344B4, dsUGT344C5, and dsUGT344A11 and the mortalities were $85.9 \%, 84.9 \%$, and $87.8 \%$, respectively, which were significantly higher than that of the control (61.0\% for DEPC water treatment and $56.3 \%$ for $d s G F P$ treatment) at the diagnostic dose of sulfoxaflor (Figure 3). While feeding on dsUGT344L2 for $48 \mathrm{~h}$ did not significantly increase the susceptibility of resistant adult aphids to sulfoxaflor, the mortality was $67.8 \%$ (Figure 3 ).

$\mathbf{A}$

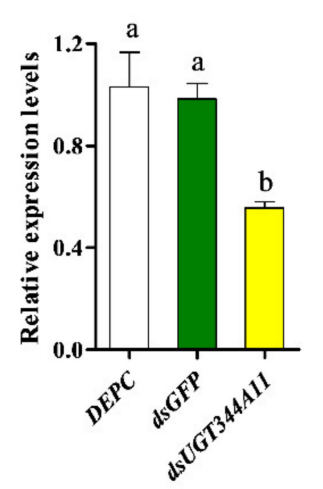

B

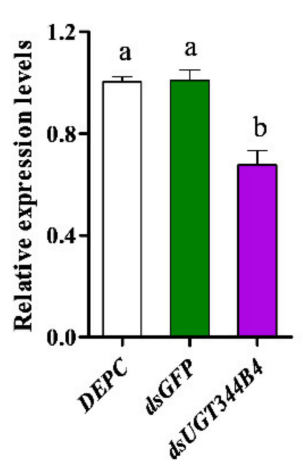

C

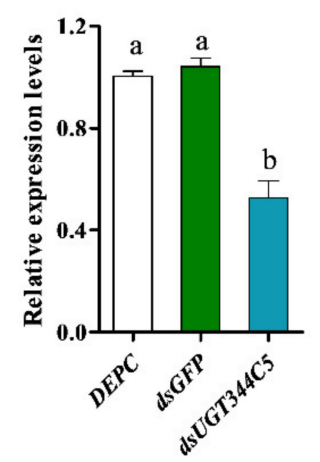

D

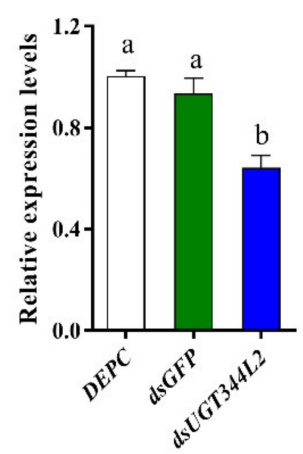

Figure 2. The transcription levels of UGT genes in Aphis gossypii fed with corresponding dsRNA $\left(100 \mathrm{ng} \mu \mathrm{L}^{-1}\right)$. The transcription levels of UGT344A11 (A), UGT344B4 (B), UGT344C5 (C), and UGT344L2 (D) in A. gossypii. The DEPC water


means are significantly different according to one-way ANOVA, followed by Tukey's multiple comparison test $(p<0.05)$.

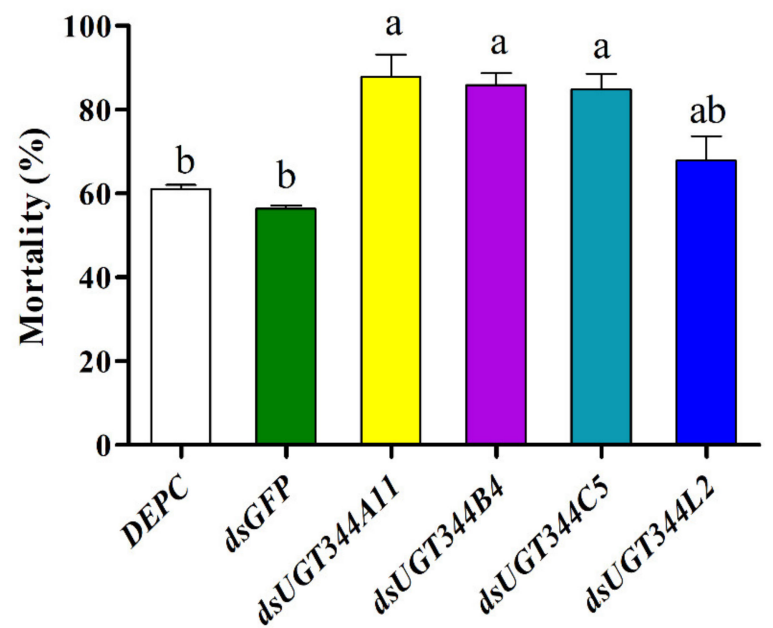

Figure 3. Effects of knockdown of UGT genes on the mortality of resistant aphids after treatment with the $\mathrm{LC}_{50}$ of sulfoxaflor for $48 \mathrm{~h}$. Different lowercase letters $(\mathrm{a}, \mathrm{b})$ with the bars indicated that the means are significantly different according to one-way ANOVA, followed by Tukey's multiple comparison test $(p<0.05)$. 


\section{Discussion}

Cotton aphids have developed high levels of resistance to a wide range of chemical insecticides in China due to the long-term and extensive application of traditional insecticides in the fields $[8,10]$. Sulfoxaflor has been used as an alternative insecticide for controlling of $A$. gossypii in China because of its high efficacy against sucking insect pests $[62,63]$. However, our previous study demonstrated that $A$. gossypii possessed high risk for developing resistance to sulfoxaflor, and further study of resistance mechanisms using a laboratory established resistant strain indicated that up-regulation of multiple P450 genes contributed to sulfoxaflor resistance [4]. In this study, to clarify the roles of phase II enzymes in the UGT family in sulfoxaflor resistance, both UGT inhibitors 5-nitrouracil and sulfinpyrazone were used in a synergism assay. The results show that two synergists significantly increased the toxicity of sulfoxaflor against resistant aphids, but showed no synergism effects against the susceptible strain (Table 2). This is in accordance with our previous study showing that 5-nitrouracil can increase the toxicity of sulfoxaflor in laboratory and two field populations [10], suggesting that enhanced UGT enzyme activities may contribute to the sulfoxaflor resistance in A. gossypii.

Although UGTs might be associated with sulfoxaflor resistance in A. gossypii, the specific genes that could play very important roles in this process are still unknown. Therefore, to determine the potential involvement of UGT genes in A. gossypii resistance to sulfoxaflor, the expression levels of 15 UGT genes were determined by using qRT-PCR, and the results show that seven of them were significantly overexpressed in the SulR strain compared with the susceptible strain. This is similar to some other studies in insects [41,54]. For example, Tian et al. found that 14 UGT genes were significantly upregulated in an imidacloprid-resistant strain of D. citri [54]. Similarly, in P. xylostella, Li et al. found that 10 UGTs were overexpressed in a multi-resistant field population (BL) compared to the SS population [40]. Interestingly, we observed that five overexpressed UGT genes belong to the UGT344 family, three of which increased expression more than 3.0-fold. Similar overexpression levels of these genes were observed in an imidacloprid-resistant strain of A. gossypii [38]. This suggests that more than one UGT gene in a family might participate in the detoxification of sulfoxaflor in A. gossypii.

To further confirm the function of overexpressed UGT genes in A. gossypii resistance to sulfoxaflor, the effects of the depressed expression of four highly upregulated UGT genes on the susceptibility to sulfoxaflor were evaluated by RNAi. Finally, we found that suppression of the expression levels of UGT344B4, UGT344C5, and UGT344A11 could significantly increase the sensitivity of sulfoxaflor resistant cotton aphids to sulfoxaflor, suggesting that these three UGT genes might participate in the detoxification process of sulfoxaflor in A. gossypii, and contribute to the development of sulfoxaflor resistance. Similar results were observed in Tetranychus cinnabarinus that silencing of UGT201D3 resulted in significantly increased susceptibility to abamectin in a resistant strain [39]. In the present study, we found that UGT344B4 plays a very important role in detoxifying sulfoxaflor, which is also confirmed in imidacloprid and thiamethoxam-resistant strains where suppression of UGT344B4 resulted in significantly increased susceptibility of A. gossypii to imidacloprid, bifenthrin [10,38], and thiamethoxam [55]. Both these results suggest that UGT344B4 might be involved in the detoxification of neonicotinoid, sulfoximine, and pyrethroid insecticides in A. gossypii. However, our results indicate that overexpression of UGT344C5 and UGT344A11 contributes to sulfoxaflor resistance in A. gossypii, which is different from the results obtained in imidacloprid and thiamethoxam-resistant strains [38,55]. This difference may be due to the differential detoxification mechanisms in A. gossypii against various types of insecticides. It is worth pointing out that our present results fail to provide direct evidence of the metabolism of sulfoxaflor by UGTs. Therefore, whether overexpressed UGTs can metabolize sulfoxaflor needs further functional research. 


\section{Conclusions}

Although our previous study demonstrated that elevated detoxification by P450 enzymes caused by overexpression of multiple P450 genes could be the main metabolic resistance mechanism of sulfoxaflor in A. gossypii, UGTs, as one type of important phase II metabolic enzymes, were also associated with the sulfoxaflor resistance in A. gossypii. These results should be useful for helping gain a better understanding of the sulfoxaflor resistance mechanisms in A. gossypii and provide valuable information for further understanding the function of UGTs in insects against insecticide stress.

Supplementary Materials: The following are available online at https:/ /www.mdpi.com/2075-445 0/12/4/356/s1, Table S1: The RPKM values of UGT genes in the susceptible (SS) and sulfoxaflor resistance (SulR) strains of Aphis gossypii.

Author Contributions: K.M. and X.G. designed the research and wrote the paper; K.M., Q.T. and P.L. carried out all the experiments and analyzed the data; and J.L. reviewed and participated in the editing of the manuscript. All authors have read and agreed to the published version of the manuscript.

Funding: This work was supported by the National Natural Science Foundation of China (Nos. 31801760 and 31871997) and the Fundamental Research Funds for the Central Universities (No. 2662019QD052).

Institutional Review Board Statement: Not applicable.

Data Availability Statement: Not applicable.

Conflicts of Interest: The authors declare no conflict of interest.

\section{References}

1. Blackman, R.L.; Eastop, V.F. Aphids on the World's Crops: An Identification Guide; John Wiley and Sons: Hoboken, NJ, USA, 1984.

2. Ricupero, M.; Desneux, N.; Zappala, L.; Biondi, A. Target and non-target impact of systemic insecticides on a polyphagous aphid pest and its parasitoid. Chemosphere 2020, 247, 125728. [CrossRef]

3. Wu, K.M.; Guo, Y.Y. The evolution of cotton pest management practices in China. Annu. Rev. Entomol. 2005, 50, 31-52. [CrossRef]

4. Ma, K.; Tang, Q.; Zhang, B.; Liang, P.; Wang, B.; Gao, X. Overexpression of multiple cytochrome P450 genes associated with sulfoxaflor resistance in Aphis gossypii Glover. Pestic. Biochem. Physiol. 2019, 157, 204-210. [CrossRef] [PubMed]

5. Koo, H.N.; An, J.J.; Park, S.E.; Kim, J.I.; Kim, G.H. Regional susceptibilities to 12 insecticides of melon and cotton aphid, Aphis gossypii (Hemiptera: Aphididae) and a point mutation associated with imidacloprid resistance. Crop Prot. 2014, 55, 91-97. [CrossRef]

6. Sun, L.; Zhou, X.; Zhang, J.; Gao, X. Polymorphisms in a carboxylesterase gene between organophosphate-resistant and -susceptible Aphis gossypii (Homoptera: Aphididae). J. Econ. Entomol. 2005, 98, 1325-1332. [CrossRef]

7. Amad, M.; Arif, M.I.; Denholm, I. High resistance of field populations of the cotton aphid Aphis gossypii Glover (Homoptera: Aphididae) to pyrethroid insecticides in Pakistan. J. Econ. Entomol. 2003, 96, 875-878. [CrossRef]

8. Chen, X.; Tie, M.; Chen, A.; Ma, K.; Li, F.; Liang, P.; Liu, Y.; Song, D.; Gao, X. Pyrethroid resistance associated with M918L mutation and detoxifying metabolism in Aphis gossypii from Bt cotton growing regions of China. Pest Manag. Sci. 2017, 73, 2353-2359. [CrossRef] [PubMed]

9. Chen, X.; Li, F.; Chen, A.; Ma, K.; Liang, P.; Liu, Y.; Song, D.; Gao, X. Both point mutations and low expression levels of the nicotinic acetylcholine receptor beta1 subunit are associated with imidacloprid resistance in an Aphis gossypii (Glover) population from a Bt cotton field in China. Pestic. Biochem. Physiol. 2017, 141, 1-8. [CrossRef] [PubMed]

10. Chen, X.; Tang, C.; Ma, K.; Xia, J.; Song, D.; Gao, X. Overexpression of UDP-glycosyltransferase potentially involved in insecticide resistance in Aphis gossypii Glover collected from Bt cotton fields in China. Pest Manag. Sci. 2019, 76, 1371-1377. [CrossRef] [PubMed]

11. Cui, L.; Qi, H.; Yang, D.; Yuan, H.; Rui, C. Cycloxaprid: A novel cis-nitromethylene neonicotinoid insecticide to control imidacloprid-resistant cotton aphid (Aphis gossypii). Pestic. Biochem. Physiol. 2016, 132, 96-101. [CrossRef]

12. Chen, Y.; Vanlerberghe-Masutti, F.; Wilson, L.J.; Barchia, I.; McLoon, M.O.; Smith, T.; Herron, G.A. Evidence of superclones in Australian cotton aphid Aphis gossypii Glover (Aphididae: Hemiptera). Pest Manag. Sci. 2013, 69, 938-948. [CrossRef] [PubMed]

13. Mostafiz, M.M.; Hassan, E.; Shim, J.; Lee, K. Insecticidal efficacy of three benzoate derivatives against Aphis gossypii and its predator Chrysoperla carnea. Ecotox. Environ. Safe. 2019, 184, 109653. [CrossRef] [PubMed]

14. Lokeshwari, D.; Krishna Kumar, N.K.; Manjunatha, H. Multiple mutations on the second acetylcholinesterase gene associated with dimethoate resistance in the melon aphid, Aphis gossypii (Hemiptera: Aphididae). J. Econ. Entomol. 2016, 109, 887-897. [CrossRef] [PubMed] 
15. Shrestha, R.B.; Parajulee, M.N. Potential cotton aphid, Aphis gossypii, population suppression by arthropod predators in upland cotton. Insect Sci. 2013, 20, 778-788. [CrossRef]

16. Bass, C.; Denholm, I.; Williamson, M.S.; Nauen, R. The global status of insect resistance to neonicotinoid insecticides. Pestic. Biochem. Physiol. 2015, 121, 78-87. [CrossRef]

17. Grant, C.; Jacobson, R.; Ilias, A.; Berger, M.; Vasakis, E.; Bielza, P.; Zimmer, C.T.; Williamson, M.S.; Ffrench-Constant, R.H.; Vontas, J.; et al. The evolution of multiple-insecticide resistance in UK populations of tomato leafminer, Tuta absoluta. Pest Manag. Sci. 2019, 75, 2079-2085. [CrossRef] [PubMed]

18. Saleem, M.; Hussain, D.; Ghouse, G.; Abbas, M.; Fisher, S.W. Monitoring of insecticide resistance in Spodoptera litura (Lepidoptera: Noctuidae) from four districts of Punjab, Pakistan to conventional and new chemistry insecticides. Crop Prot. 2016, 79, 177-184. [CrossRef]

19. Umina, P.A.; Lord, A.; Micic, S.; Edwards, O. Discovery and characterisation of field resistance to organophosphorus chemicals in a major mite pest, Halotydeus destructor. Pest Manag. Sci. 2017, 73, 1719-1724. [CrossRef]

20. Voudouris, C.; Kati, A.N.; Sadikoglou, E.; Williamson, M.; Skouras, P.J.; Dimotsiou, O.; Georgiou, S.; Fenton, B.; Skavdis, G.; Margaritopoulos, J.T. Insecticide resistance status of Myzus persicae in Greece: Long-term surveys and new diagnostics for resistance mechanisms. Pest Manag. Sci. 2016, 72, 671-683. [CrossRef]

21. Ziapour, S.P.; Kheiri, S.; Fazeli-Dinan, M.; Sahraei-Rostami, F.; Mohammadpour, R.A.; Aarabi, M.; Nikookar, S.H.; Sarafrazi, M.; Asgarian, F.; Enayati, A.; et al. Pyrethroid resistance in Iranian field populations of Rhipicephalus (Boophilus) annulatus. Pestic. Biochem. Physiol. 2017, 136, 70-79. [CrossRef]

22. Dawkar, V.V.; Chikate, Y.R.; Lomate, P.R.; Dholakia, B.B.; Gupta, V.S.; Giri, A.P. Molecular insights into resistance mechanisms of Lepidopteran insect pests against toxicants. J. Proteome Res. 2013, 12, 4727-4737. [CrossRef]

23. Cao, C.; Zhang, J.; Gao, X.; Liang, P.; Guo, H. Overexpression of carboxylesterase gene associated with organophosphorous insecticide resistance in cotton aphids, Aphis gossypii (Glover). Pestic. Biochem. Physiol. 2008, 90, 175-180. [CrossRef]

24. Field, L.; Williamson, M.; Moores, G.; Devonshire, A. Cloning and analysis of the esterase genes conferring insecticide resistance in the peach-potato aphid, Myzus persicae (sulzer). Biochem. J. 1993, 294, 569-574. [CrossRef] [PubMed]

25. Gong, Y.; Ai, G.; Li, M.; Shi, X.; Diao, Q.; Gao, X. Functional characterization of carboxylesterase gene mutations involved in Aphis gossypii resistance to organophosphate insecticides. Insect Mol. Biol. 2017, 26, 702-714. [CrossRef] [PubMed]

26. Pavlidi, N.; Vontas, J.; Van Leeuwen, T. The role of glutathione $S$-transferases (GSTs) in insecticide resistance in crop pests and disease vectors. Curr. Opin. Insect Sci. 2018, 27, 97-102. [CrossRef]

27. Li, X.; Li, R.; Zhu, B.; Gao, X.; Liang, P. Overexpression of cytochrome P450 CYP6BG1 may contribute to chlorantraniliprole resistance in Plutella xylostella (L.). Pest Manag. Sci. 2017, 74, 1386-1393. [CrossRef]

28. Bass, C.; Carvalho, R.A.; Oliphant, L.; Puinean, A.M.; Field, L.M.; Nauen, R.; Williamson, M.S.; Moores, G.; Gorman, K. Overexpression of a cytochrome P450 monooxygenase, CYP6ER1, is associated with resistance to imidacloprid in the brown planthopper, Nilaparvata lugens. Insect Mol. Biol. 2011, 20, 763-773. [CrossRef]

29. Ding, Z.; Wen, Y.; Yang, B.; Zhang, Y.; Liu, S.; Liu, Z.; Han, Z. Biochemical mechanisms of imidacloprid resistance in Nilaparvata lugens: Over-expression of cytochrome P450 CYP6AY1. Insect Biochem. Mol. Biol. 2013, 43, 1021-1027. [CrossRef] [PubMed]

30. Liao, X.; Jin, R.; Zhang, X.; Ali, E.; Mao, K.; Xu, P.; Li, J.; Wan, H. Characterization of sulfoxaflor resistance in the brown planthopper, Nilaparvata lugens (Stal). Pest Manag. Sci. 2018, 75, 1646-1654. [CrossRef]

31. Sun, X.; Gong, Y.; Ali, S.; Hou, M. Mechanisms of resistance to thiamethoxam and dinotefuran compared to imidacloprid in the brown planthopper: Roles of cytochrome P450 monooxygenase and a P450 gene CYP6ER1. Pestic. Biochem. Physiol. 2018, 150, 17-26. [CrossRef] [PubMed]

32. Zhang, Y.; Yang, Y.; Sun, H.; Liu, Z. Metabolic imidacloprid resistance in the brown planthopper, Nilaparvata lugens, relies on multiple P450 enzymes. Insect Biochem. Mol. Biol. 2016, 79, 50-56. [CrossRef] [PubMed]

33. Jin, R.; Mao, K.; Liao, X.; Xu, P.; Li, Z.; Ali, E.; Wan, H.; Li, J. Overexpression of CYP6ER1 associated with clothianidin resistance in Nilaparvata lugens (Stal). Pestic. Biochem. Physiol. 2019, 154, 39-45. [CrossRef]

34. Field, L.M.; Blackman, R.L.; Tyler-Smith, C.; Devonshire, A.L. Relationship between amount of esterase and gene copy number in insecticide-resistant Myzus persicae (Sulzer). Biochem. J. 1999, 339, 737-742. [CrossRef] [PubMed]

35. Field, L.M.; Devonshire, A.L. Evidence that the E4 and FE4 esterase genes responsible for insecticide resistance in the aphid Myzus persicae (Sulzer) are part of a gene family. Biochem. J. 1998, 330, 169-173. [CrossRef]

36. Tang, Q.; Ma, K.; Hou, Y.; Gao, X. Monitoring insecticide resistance and diagnostics of resistance mechanisms in the green peach aphid, Myzus persicae (Sulzer) (Hemiptera: Aphididae) in China. Pestic. Biochem. Physiol. 2017, 143, 39-47. [CrossRef]

37. Pan, Y.; Xu, P.; Zeng, X.; Liu, X.; Shang, Q. Characterization of UDP-glucuronosyltransferases and the potential contribution to nicotine tolerance in Myzus persicae. Int. J. Mol. Sci. 2019, 20, 3637. [CrossRef] [PubMed]

38. Chen, X.; Xia, J.; Shang, Q.; Song, D.; Gao, X. UDP-glucosyltransferases potentially contribute to imidacloprid resistance in Aphis gossypii glover based on transcriptomic and proteomic analyses. Pestic. Biochem. Physiol. 2019, 159, 98-106. [CrossRef]

39. Wang, M.; Liu, X.; Shi, L.; Liu, J.; Shen, G.; Zhang, P.; Lu, W.; He, L. Functional analysis of UGT201D3 associated with abamectin resistance in Tetranychus cinnabarinus (Boisduval). Insect Sci. 2020, 27, 276-291. [CrossRef] [PubMed]

40. Li, X.; Shi, H.; Gao, X.; Liang, P. Characterization of UDP-glucuronosyltransferase genes and their possible roles in multiinsecticide resistance in Plutella xylostella (L.). Pest Manag. Sci. 2018, 74, 695-704. [CrossRef] [PubMed] 
41. Li, X.; Zhu, B.; Gao, X.; Liang, P. Over-expression of UDP-glycosyltransferase gene UGT2B17 is involved in chlorantraniliprole resistance in Plutella xylostella (L.). Pest Manag. Sci. 2017, 73, 1402-1409. [CrossRef]

42. Ahn, S.; Vogel, H.; Heckel, D. Comparative analysis of the UDP-glycosyltransferase multigene family in insects. Insect Biochem. Mol. Biol. 2012, 42, 133-147. [CrossRef] [PubMed]

43. Ahn, S.; Badenes-Perez, F.; Reichelt, M.; Svatos, A.; Schneider, B.; Gershenzon, J.; Heckel, D. Metabolic detoxification of capsaicin by UDP-glycosyltransferase in three Helicoverpa species. Arch. Insect Biochem. Physiol. 2011, 78, 104-118. [CrossRef] [PubMed]

44. Bock, K. The UDP-glycosyltransferase (UGT) superfamily expressed in humans, insects and plants: Animal-plant arms-race and co-evolution. Biochem. Pharmacol. 2016, 99, 11-17. [CrossRef]

45. Bock, K. Vertebrate UDP-glucuronosyltransferases: Functional and evolutionary aspects. Biochem. Pharmacol. 2003, 66, 691-696. [CrossRef]

46. Meech, R.; Hu, D.G.; McKinnon, R.A.; Mubarokah, S.; Haines, A.; Nair, P.; Rowland, A.; Mackenzie, P. The UDPglycosyltransferase (UGT) superfamily: New members, new functions, and novel paradigms. Physiol. Rev. 2019, 99, 1153-1222. [CrossRef]

47. Ahmad, S.; Hopkins, T. Phenol $\beta$-glucosyltransferase and bglucosidase activities in the tobacco hornworm larva Manduca sexta (L.): Properties and tissue localization. Arch. Insect Biochem. 1992, 21, 207-224. [CrossRef]

48. Kojima, W.; Fujii, T.; Suwa, M.; Miyazawa, M.; Ishikawa, Y. Physiological adaptation of the Asian corn borer Ostrinia furnacalis to chemical defenses of its host plant, maize. J. Insect Physiol. 2010, 56, 1349-1355. [CrossRef]

49. Krempl, C.; Sporer, T.; Reichelt, M.; Ahn, S.; Heidel-Fischer, H.; Vogel, H.; Heckel, D.G.; Joussen, N. Potential detoxification of gossypol by UDP-glycosyltransferases in the two Heliothine moth species Helicoverpa armigera and Heliothis virescens. Insect Biochem. Mol. Biol. 2016, 71, 49-57. [CrossRef]

50. Wouters, F.; Reichelt, M.; Glauser, G.; Bauer, E.; Erb, M.; Gershenzon, J.; Vassao, D. Reglucosylation of the benzoxazinoid DIMBOA with inversion of stereochemical configuration is a detoxification strategy in Lepidopteran herbivores. Angew. Chem. Int. Ed. Engl. 2014, 126, 11502-11506. [CrossRef]

51. Kaplanoglu, E.; Chapman, P.; Scott, I.M.; Donly, C. Overexpression of a cytochrome P450 and a UDP-glycosyltransferase is associated with imidacloprid resistance in the Colorado potato beetle, Leptinotarsa decemlineata. Sci. Rep. 2017, 7, 1762. [CrossRef]

52. Zhou, Y.; Fu, W.; Si, F.; Yan, Z.; Zhang, Y.; He, Q.; Chen, B. UDP-glycosyltransferase genes and their association and mutations associated with pyrethroid resistance in Anopheles sinensis (Diptera: Culicidae). Malaria J. 2019, 18, 62. [CrossRef] [PubMed]

53. Zhao, J.; Xu, L.; Sun, Y.; Song, P.; Han, Z. UDP-glycosyltransferase genes in the striped rice stem borer, Chilo suppressalis (Walker), and their contribution to chlorantraniliprole resistance. Int. J. Mol. Sci. 2019, 20, 1064. [CrossRef]

54. Tian, F.; Wang, Z.; Li, C.; Liu, J.; Zeng, X. UDP-Glycosyltransferases are involved in imidacloprid resistance in the Asian citrus psyllid, Diaphorina citri (Hemiptera: Lividae). Pestic. Biochem. Physiol. 2019, 154, 23-31. [CrossRef]

55. Pan, Y.; Tian, F.; Wei, X.; Wu, Y.; Gao, X.; Xi, J.; Shang, Q. Thiamethoxam resistance in Aphis gossypii Glover relies on multiple UDP-glucuronosyltransferases. Front. Physiol. 2018, 9, 322. [CrossRef] [PubMed]

56. Jiang, H.; Tian, Y.; Yan, W.; Chen, J.; Zhang, Z.; Xu, H. Drip chemigation of flonicamid effectively controls cotton aphid (Aphis gossypii) and is benign to lady beetle (Coccinella septempunctata) and lacewing larva (Chrysoperla sinica). Crop Prot. 2020, 129, 105039. [CrossRef]

57. Ma, K.; Tang, Q.; Xia, J.; Lv, N.; Gao, X. Fitness costs of sulfoxaflor resistance in the cotton aphid, Aphis gossypii Glover. Pestic. Biochem. Physiol. 2019, 158, 40-46. [CrossRef] [PubMed]

58. Moores, G.; Gao, X.; Denholm, I.; Devonshire, A. Characterisation of insensitive acetylcholinesterase in insecticide-resistant cotton aphids, Aphis gossypii Glover (Homoptera: Aphididae). Pestic. Biochem. Physiol. 1996, 56, 102-110. [CrossRef]

59. Ma, K.; Li, F.; Liang, P.; Chen, X.; Liu, Y.; Tang, Q.; Gao, X. RNA interference of Dicer-1 and Argonaute-1 increasing the sensitivity of Aphis gossypii Glover (Hemiptera: Aphididae) to plant allelochemical. Pestic. Biochem. Physiol. 2017, 138, 71-75. [CrossRef]

60. Ma, K.; Li, F.; Liang, P.; Chen, X.; Liu, Y.; Gao, X. Identification and validation of reference genes for the normalization of gene expression data in qRT-PCR analysis in Aphis gossypii (Hemiptera: Aphididae). J. Insect Sci. 2016, 16, 1-9. [CrossRef]

61. Livak, K.; Schmittgen, T. Analysis of relative gene expression data using real-time quantitative PCR and the $2^{-\Delta \Delta C T}$ method. Methods 2001, 25, 402-408. [CrossRef]

62. Zhu, Y.; Loso, M.; Watson, G.; Sparks, T.; Rogers, R.; Huang, J.; Gerwick, B.; Babcock, J.; Kelley, D.; Hegde, V.; et al. Discovery and characterization of sulfoxaflor, a novel insecticide targeting sap-feeding pests. J. Agric. Food Chem. 2011, 59, 2950-2957. [CrossRef] [PubMed]

63. Babcock, J.; Gerwick, C.; Huang, J.; Loso, M.; Nakamura, G.; Nolting, S.; Rogers, R.; Sparks, T.; Thomas, J.; Watson, G.; et al. Biological characterization of sulfoxaflor, a novel insecticide. Pest Manag. Sci. 2011, 67, 328-334. [CrossRef] [PubMed] 